\title{
Solid Dosage Forms: A Detailed Research on Non-conforming Product Quality
}

\author{
Katta Hemanth G', Ravindra Shenoy U², Girish Thunga ${ }^{3}$, Sudeep Kumar Agrawal ${ }^{4}$, Mahendra Joshi ${ }^{5}$, \\ Muddukrishna Badamane Sathyanarayana ${ }^{6}$, Vamshi Krishna Tippavajhala', Abhinaya N1, \\ Girish Pai Kulyadi ${ }^{1, *}$
}

\author{
1Department of Pharmaceutics, Manipal College of Pharmaceutical Sciences, Manipal Academy of Higher Education, Manipal, \\ Karnataka, INDIA. \\ 2Department of Commerce, Manipal Academy of Higher Education, Manipal, Karnataka, INDIA. \\ ${ }^{3}$ Department of Pharmacy Practice, Manipal College of Pharmaceutical Sciences, Manipal Academy of Higher Education, Manipal, \\ Karnataka, INDIA. \\ ${ }^{4}$ Product Development, Sun Pharmaceutical Industries Ltd., Vadodara, Gujarat, INDIA. \\ ${ }^{5}$ Research and Development, IDRS Labs Pvt. Ltd., Bangalore, Karnataka, INDIA. \\ ${ }^{6}$ Department of Pharmaceutical Quality Assurance, Manipal College of Pharmaceutical Sciences, Manipal Academy of Higher \\ Education, Manipal, Karnataka, INDIA.
}

\begin{abstract}
Introduction: Any defects in pharmaceutical products lead to minor, major, or critical deviation and if such a product is released, it also leads to product recalls and legal actions. In such cases, the concern is about patient's safety rather than the company's economy and fame. This study aimed to investigate the various quality defects which have occurred in marketed tablets. Materials and Methods: The investigation was carried out which involved identification of defects, categorizing the type, root causes, suggesting remedial measures and documenting the clinical significance of defective dosage forms of tablets. Dosage forms included were film-coated tablets, uncoated tablets, uncoated caplet shaped tablets and dispersible tablets which are prescribed for their specific therapeutic activity. Results: This research work has revealed quality issues of minor, major and critical types. These defects were unique in nature and appeared to be stray incidents which were not available even in standard textbooks or literature. Conclusion: Medicines being the silver sword to treat an ailment in a patient, it should not involve any quality issues leading to a significant impact on the safety and efficacy of the prescribed drug. It is essential to embed an attentive and dedicated quality assurance ( $Q A$ ) team and adhere to all the regulations laid by regulatory agencies in the pharmaceutical setup thereby ensuring that high-quality medicines are supplied and the safety of the patient is shielded.
\end{abstract}

Key words: Tablets, Solid dosage forms, Tablet defects, Patient perception, Investigation, Quality Assurance.

\section{INTRODUCTION}

The drug is defined as a substance recognized by official pharmacopoeia / In house (IH) which, is intended for its use in the diagnosis, cure, mitigation, treatment, or prevention of disease. Rarely drug is given in its pure chemical form. To ease the drug administration by a human being, it is essential to convert it into physical form in which drug is dispensed known as dosage form. ${ }^{1,2}$
The dosage form is a package of Active Pharmaceutical Ingredient (API) along with selective non medicinal compounds known as excipients. These non-medicinal compounds may be used to flavor, solubilize, color, preserve, dilute, emulsify, suspend and thicken medicinal agents into efficacious and appealing dosage forms. ${ }^{3}$

Besides dispensing the drug into physical form, the dosage form is needed for the following additional reasons:
Submission Date: 23-04-2020; Revision Date: 14-07-2020; Accepted Date: 02-10-2020

DOI: 10.5530/ijper.54.3s.146 Correspondence: Dr. Girish Pai Kulyadi Assistant Professor, Selection Grade, Department of Pharmaceutics, Manipal College of Pharmaceutical Sciences, Manipal Academy of Higher Education,

Manipal-576104, Karnataka, INDIA.

Phone: +919008135597

E-mail: girish.pai@manipal. edu

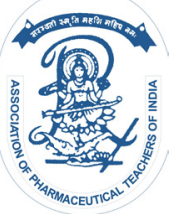

www.ijper.org 
1. Protection of drugs from the external environment (Oxygen or humidity, e.g. coated tablets, sealed ampules) and internal environment (Gastric acid, e.g. enteric coated tablets).

2. Masking the bitter, salty and noxious taste of pure form of drug i.e. Palatability. E.g. Capsules, flavored syrups.

3. Ease administration through the body's orifices. E.g. Rectal suppositories and vaginal pessaries.

4. To provide therapeutic action at the site of administration. E.g. Transdermal patches, creams, ointments, ear and nasal drops. ${ }^{3}$

Figure 1 lists the various dosage forms based on their route of administration. ${ }^{3}$ There might exist two or more dosage form for a particular drug, which aims in satisfying patient and physician need. Clinical indications intended to treat, systemic or local therapy, duration of action required are factors to be considered while selecting a dosage form. ${ }^{1}$

There are various dosage forms for the oral route of administration, but tablets are the most popular ones. Because of their availability and patient compliance, they are the most preferred ones and constitute $90 \%$ of dosage forms prescribed when the drug has to enter systemic circulation by the oral route of administration., Tablet can be defined as a unit solid dosage form prepared by compression or molding that contains medicinal substances with or without diluents, disintegrates and other pharmaceutical adjuncts. ${ }^{1}$ Figure 2 gives the classification of tablets based on coating.

\section{Packaging}

Any product to reach from the manufacturer to the enduser must be packed accordingly to protect itself from the external environment. In the same context especially pharmaceutical products need packaging which is superior to other products so that the product fulfils its main requirement, i.e., uniformity, safety, efficacy, integrity, purity and thereby exhibiting good shelf-life stability profile. ${ }^{5}$

Packaging can be defined as a process which confines pharmaceutical product from its genesis in production unit till it reaches the end user. ${ }^{6}$

Factors influencing the type of packaging used for the pharmaceutical product:

a. Type of dosage form through which drug will be delivered

b. Route of administration intended for drug delivery

c. The mode from which the medicines will be sold

$\mathrm{d}$. The technique used in dispensing via a combined device/pack.

\section{Different Types of Packaging}

Based on the level of contact of formulation with the container

1. Primary packaging: This packaging material is in direct contact with the formulation. Hence it is mandatory to ensure that packaging material doesn't interact with the drug. E.g. blister packs, strip packs, containers of liquid dosage forms, etc.

2. Secondary packaging: This packaging type is in contact with primary packaging, keeping multiple units of products in place during transportation. E.g. 1-ply, 2-ply and 3-ply corrugated boxes.

3. Tertiary packaging: This packaging material conceals the above two units of packed products and is in direct contact with secondary packaging. E.g. shrink wraps, plain boxes, cardboards ${ }^{6,7}$

Usually, the secondary package is a composite of primary packaging material with the product and Patient information leaflet (PIL). PIL is a document added by the manufacturer which gives information about clinical indications of the drug, type of dosage form, route of administration, storage condition, adverse drug reactions, contraindications and details of the manufacturer. ${ }^{8}$

\section{Packaging types used for tablets}

a. Blister packaging: $\mathrm{WHO}$ defines a blister pack as a multi-dose container consisting of two layers, of which one is shaped to contain the individual doses and is heat-sealed with other layer which may be aluminum, paper, or PET (Polyethylene tetraphthalate).

b. Strip packaging: As per WHO strip pack is defined as A multi-dose container consisting of two layers, usually provided with perforations, suitable for containing single doses of solid or semi-solid preparations. The two layers are made of heatsealable paper alloy, aluminum films, glassine. ${ }^{9,10}$

Both above-mentioned packaging types involve sealing of individual doses, which requires breaking or tearing of individual compartment before administration. ${ }^{3}$

The major difference between the above two types is, the former has cavities on thermoplastic which are preformed and the tablet is dropped before closing the cavity. Whereas in later, the tablet is dropped in between the two layers in which it has to be embedded and sealed. ${ }^{10}$

\section{Packaging materials used for tablets}

1. Polyvinyl Chloride (PVC): PVC is highly moisture resistant and is available in different gauges. It can be transparent or can be made opaque or can be tinted 
in different colors to block specific wavelengths of light. It is the most commonly used blister material because of its affordability and its characteristics like flexibility, thermoforming and rigidity. ${ }^{11}$

\section{Polychlorotrifluroethylene}

(PCTFE)

laminations: It is thermoplastic manufactured by modification of polyethylene (PE). It is fixed to PVC by the aid of adhesive.

3. Aluminum: The various combination of packs is formed by combining. E.g. Alu-Alu, Aluminumpaper, aluminum-PET. Aluminum is widely used in strip packs and as lid material in the blister pack.

4. Cellulose polymers: Are the main components of paper-based packs. Based on the concentration pulp they are used as lid material for Aluminum or PVC blister packs

These are the materials used in the packaging of tablets. However, the manufacturer cannot use material of his choice to prepare containers or packages for any dosage form. The list of materials published by the FDA (Food and Drug Administration) which are "Generally regarded as safe (GRAS)" have to be used in packaging material. If the manufacturer intends to use a material that is out of the GRAS list, he has to conduct tests for the intended material and file a New Drug Application to FDA. ${ }^{10,12-14}$

\section{Defects in Tablet manufacturing}

Figure 3 gives the classification of Defects based on their occurrence in coated and uncoated tablets. The tablet manufacturing process involves several unit operations from which defects in tablets arise. Though there are significant innovative solutions that have come up in the manufacturing process there is no decrease in cases of tablet defects. ${ }^{15,16}$ Both to the manufacturer (e.g. simplicity and economy of the preparation, stability, and convenience in packing, shipping and dispensing

Few major defects have been discussed below:

\section{Capping}

It is identified when there is partial or complete separation of the top or bottom crowns of tablets Causes:

- Deep concave punches and poorly finished dies

- Over lubrication or very low moisture content of granules

- High compression pressure

- Deformational properties of ingredients

- Incorrect set up of the tableting machine

Remedies:

- Implementing flat punches and polishing dies appropriately
- Pre-compression and decreasing the compression pressure

- Ensure proper setup of tableting machine. ${ }^{14,16}$

\section{Cracking}

In Uncoated tablets: Cracking can be described as small cracks that occur in upper and lower surfaces of tablets.

Causes:

- Due to usage of large size and dry granules

- Due to entrapment of air in granules during punching.

Remedies:

- Reduce the size of granules, incorporate fines along and maintain the standard amount of moisture in granules

- Use tapered die.

In Coated tablets: Cracking is a defect in which cracks occur along with the crown of tablet or splits along the edges of a tablet (Splitting).

Causes:

- Due to internal stress developed within film after tablet dries

- Usage of high molecular weight polymer for tablet coating.

Remedies:

- Implementation of post compaction relaxation phenomena after tablet punching

- Addition of plasticizer into coating material thereby increasing the flexibility of tablet coat. . $^{14,16,17}$

3. Orange peel effect: It is a surface-based defect. The coated tablet looks rough and non-glossy.

Causes:

- Premature drying of atomized droplets or spraying of a viscous coating solution

- Tablets subjected to a rapid drying process.

Remedies:

- Decreasing the viscosity of coating solution by adding other solvents

- Subject tablets to mild drying conditions. ${ }^{16,17}$

Our mankind involves day to day activities which involve sectors like architecture, agriculture, fashion, transport, telecommunication and pharma. Defects in none of the sectors are tolerated. In the same lines, defects in any pharmaceutical product may be fatal. Although Pharmaceutical sector is constrained by stringent regulations laid by Regulatory agencies, (United States Food and Drug Administration, European Medicines Agency, Central Drugs Standard Control Organization, Therapeutics Goods Administration and Medicines 


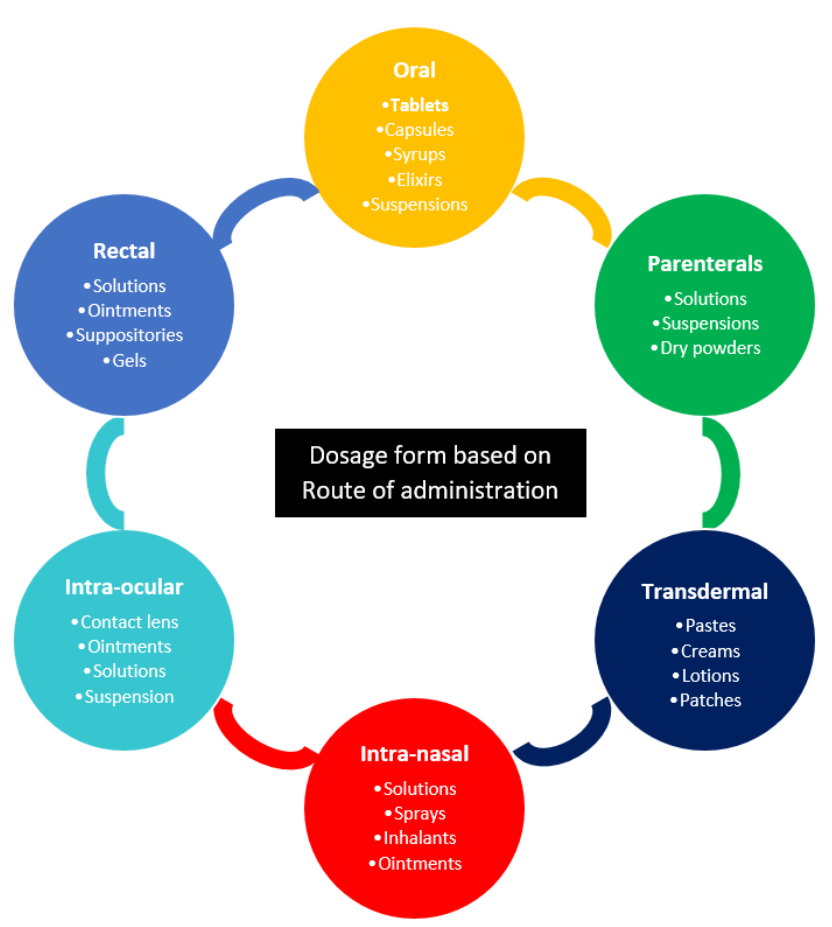

Figure 1: Illustration of various dosage forms.

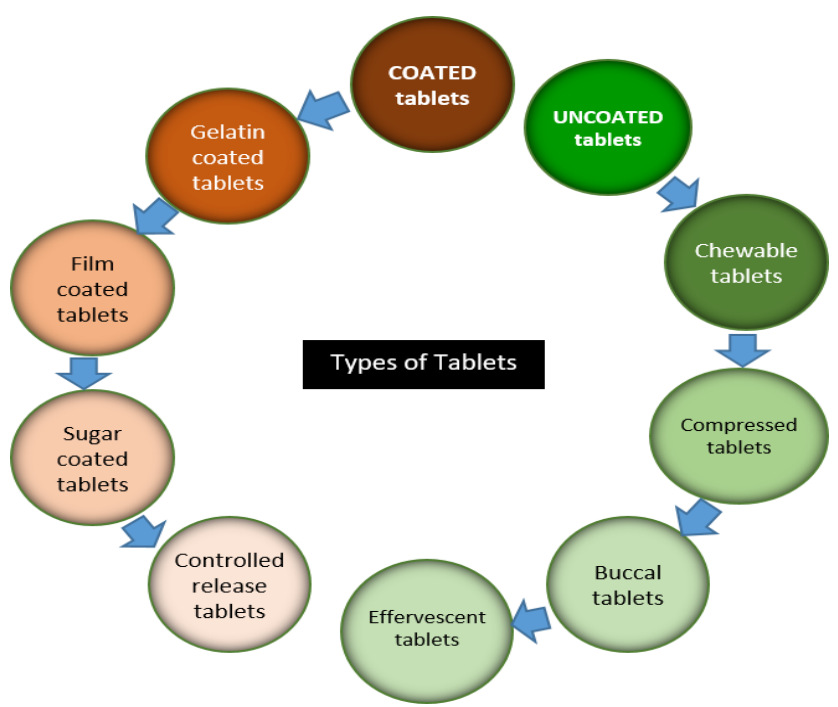

Figure 2: Classification of Tablets based on coating.

and Healthcare Regulatory Agency) defects have been occurring which may have a clinical effect on the patient and economical significance on the manufacturer.

In this article, we present our case studies which involve research on product defects or quality issues. Our research work involved a unique in-house mechanism that started from the identification of a product, procurement of products and its detailed study. The following are the case studies/defects and based on the detailed investigation we have identified the category of complaint, probable root causes, remediation and

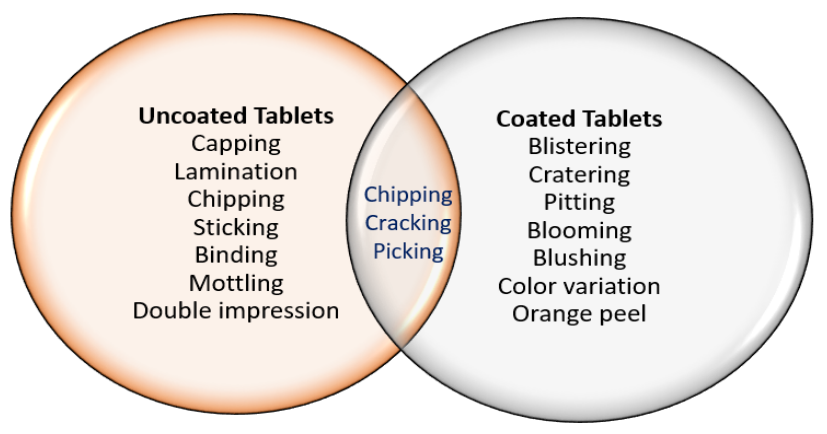

Figure 3: Defects in tablets based on their occurrence in coated and uncoated tablets.

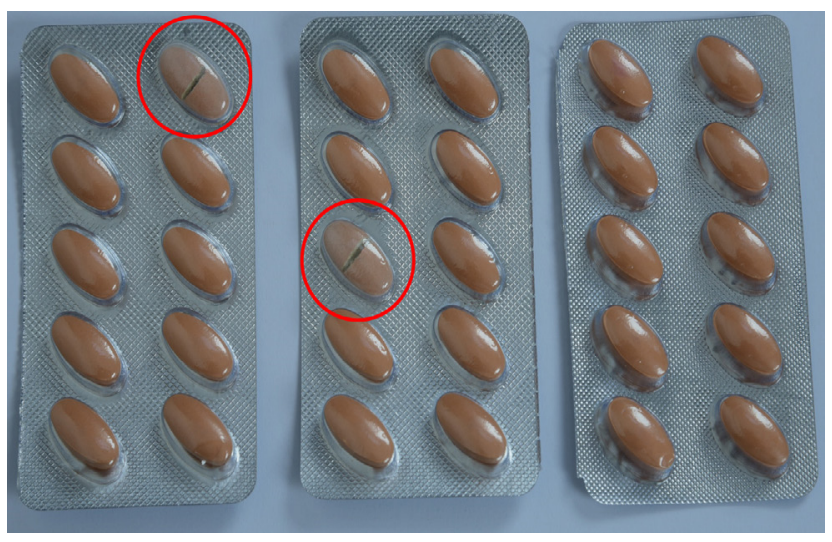

Figure 4: Evidence showing broken film coated tablets (2 LHS blisters) and good blister (RHS).

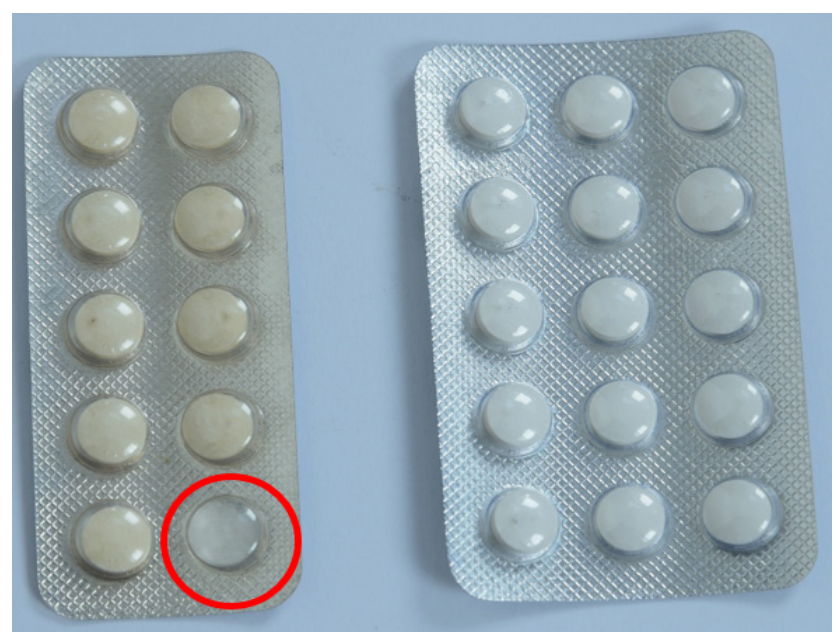

Figure 5: Evidence showing empty pocket (LHS) and one good blister of same brand (RHS).

clinical significance of complaint. Table 1. Gives an overview of dosage forms and investigated defects.

\section{CASE STUDY 1 - Investigation of broken film coated tablets}

Dosage form: Film coated tablets.

Generic Name: Flavonoids. ${ }^{18}$ 


\begin{tabular}{|c|c|c|c|}
\hline \multicolumn{3}{|c|}{ Table 1: Overview of Investigated defective products. } \\
\hline $\begin{array}{c}\text { Case } \\
\text { No. }\end{array}$ & $\begin{array}{c}\text { Dosage } \\
\text { form }\end{array}$ & Generic name & Defect \\
\hline 1 & $\begin{array}{c}\text { Film coated } \\
\text { tablets }\end{array}$ & Flavanoids & $\begin{array}{c}\text { Broken film coated } \\
\text { tablets within intact } \\
\text { blister pocket }\end{array}$ \\
\hline 2 & $\begin{array}{c}\text { Uncoated } \\
\text { tablets }\end{array}$ & $\begin{array}{c}\text { Levocetrizine } \\
\text { hydrochloride }\end{array}$ & $\begin{array}{c}\text { Empty blister } \\
\text { pocket }\end{array}$ \\
\hline 3 & $\begin{array}{c}\text { Uncoated } \\
\text { tablets }\end{array}$ & $\begin{array}{c}\text { Glibenclamide } \\
\text { and Metformin } \\
\text { hydrochloride }\end{array}$ & $\begin{array}{c}\text { Presence of Hair } \\
\text { follicle within } \\
\text { two intact blister } \\
\text { pockets }\end{array}$ \\
\hline 4 & $\begin{array}{c}\text { Film coated } \\
\text { tablets }\end{array}$ & $\begin{array}{c}\text { Desloratadine } \\
\text { Soiled and } \\
\text { powders adhered } \\
\text { to tablets }\end{array}$ \\
\hline 5 & $\begin{array}{c}\text { Uncoated } \\
\text { caplet } \\
\text { shaped } \\
\text { tablets }\end{array}$ & $\begin{array}{c}\text { Paracetamol } \\
\text { and Aceclofenac } \\
\text { sodium }\end{array}$ & $\begin{array}{c}\text { Spoiled and fragile } \\
\text { tablet }\end{array}$ \\
\hline 6 & $\begin{array}{c}\text { Dispersible } \\
\text { tablets }\end{array}$ & $\begin{array}{c}\text { Lactic acid } \\
\text { bacillus, Folic acid } \\
\text { and Vitamin B }\end{array}$ & \begin{tabular}{c} 
Empty blister sheet \\
\hline
\end{tabular} \\
\hline
\end{tabular}

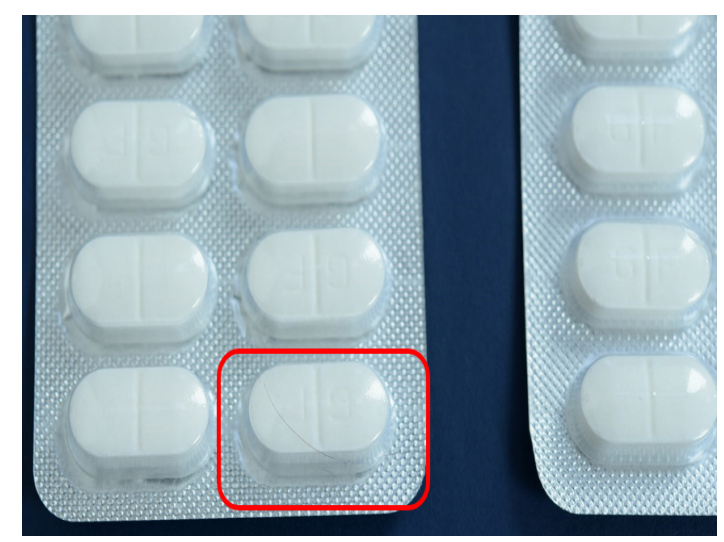

Figure 6 (a): Evidence showing hair follicle (Blister 1).

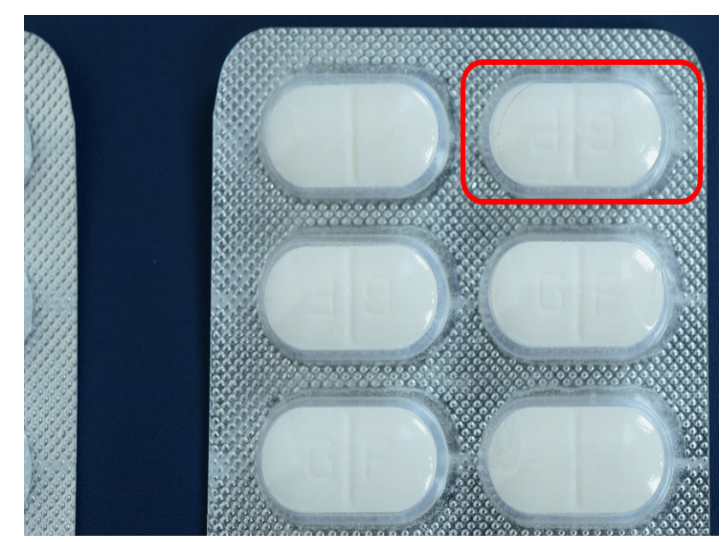

Figure 6 (b): Evidence showing hair follicle (Blister 2).

Therapeutic category: Phlebotropic/Venoactive drug. ${ }^{19}$

Defects: Broken film coated tablets are found within intact blister pocket (Figure 4).

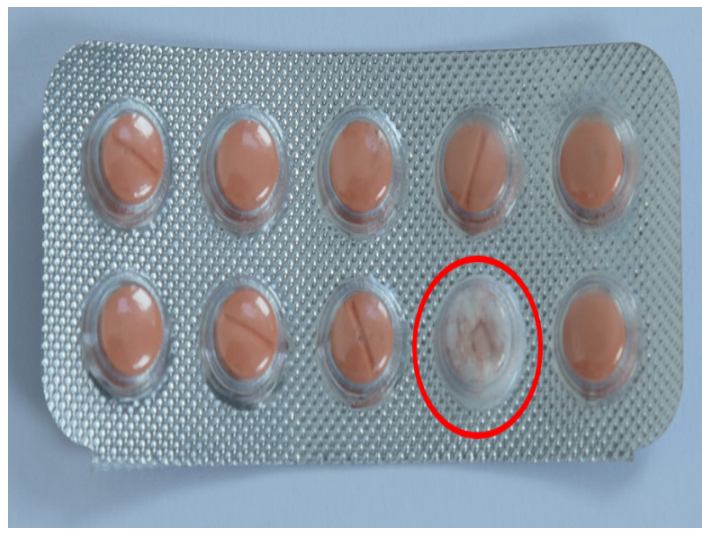

Figure 7: Evidence showing soiled film coated tablet.

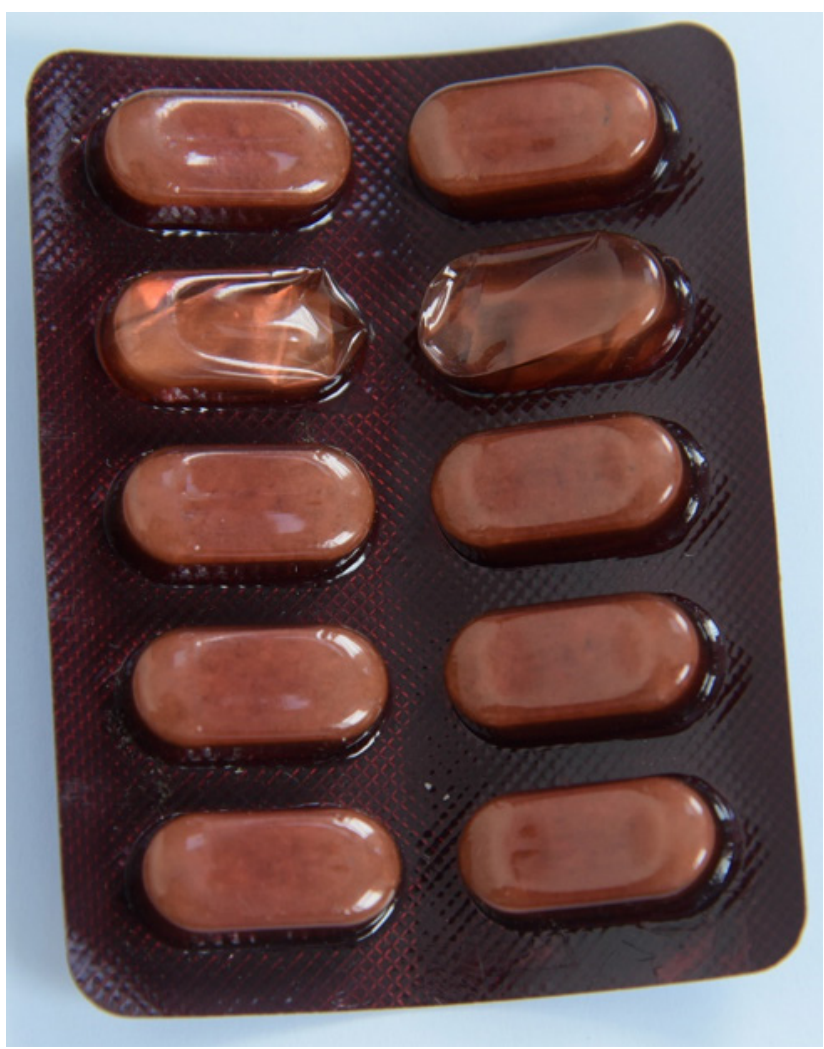

Figure 8 (a): Amber colored blister containing spoiled tablets.

\section{Category of complaint: Major}

Probable root causes:

- Low hardness of tablets. ${ }^{3}$

- Improper machine setting during packaging.

- Improperly designed packaging change parts having a very low clearance of the pocket.

- Selection of inadequate packing material - film former or lidding foil leading to high moisture uptake. $^{20}$

- Inadequate training to operators involved in packing. 


\section{Remediation}

$>$ To check whether the tablet meets the required hardness specifications. ${ }^{21}$ Improve tablet formulation leading to improved hardness if found low.

$>$ Review the film former and lidding foil quality with respect to its Water Vapor Transmission Rate $(\text { WVTR })^{22}$ and propensity of the lidding foil to have pin holes. Use film former with better barrier properties and higher thickness of lidding foil. ${ }^{12}$

$>$ Increase the pocket depth by getting new dies for the film formation.

$>$ Recalibrate recipe of the pocket formation steps by increasing film-forming temperature and vacuum.

$>$ Impart training to packaging personnel to adhere to the prescribed machine settings and calibrating the temperature and vacuum sensors.

\section{Clinical Significance}

Reduced patient compliance. Altered therapeutic efficacy due to the degradation of API. Reduced bioavailability due to altered dissolution. The stability of active ingredient ${ }^{23}$ may be affected due to exposure of the product to low gastric $\mathrm{pH}$.

\section{CASE STUDY 2 - Investigation of empty blister pocket}

Dosage form: Uncoated tablets

Generic Name: Levocetirizine hydrochloride tablets ${ }^{24}$ Therapeutic category: Selective histamine $\mathrm{H} 1$ receptor antagonist, with antihistamine, anti-inflammatory and potential anti-angiogenic activities ${ }^{25}$

Defects: Empty pocket found in intact blister (Figure. 5).

\section{Category of complaint: Minor}

Probable root causes

- Inadequate in-process quality checks during primary packing $^{26}$

- Camera based inspection was not carried out ${ }^{27}$

\section{Remediation}

$>$ Implementation of automatic check weigher to reject underweight blisters.

$>$ Camera based visual check to reject blisters with empty pockets.

$>$ Cleaning of tablet delivery chutes to the blister to ensure uniform flow of tablets to the blisters.

Clinical Significance: Patient acceptance decreases and the patient may discontinue purchasing the same brand again.

\section{CASE STUDY 3 - Investigation of the tablet with hair follicle}

Dosage form: Uncoated tablets
Generic Name: Glibenclamide and Metformin hydrochloride tablets ${ }^{28}$

Therapeutic category: Antidiabetic

Defects: Hair follicle found within TWO intact blister pockets (Figure 6a \& 6b).

\section{Category of complaint: Critical}

\section{Probable root causes}

- Staff not wearing hand gloves.

- Inadequate training on gowning procedure ${ }^{29}$

- Inadequate environmental control.

- Use of poor quality of film former and/or quality check.

\section{Remediation}

> Strict adherence to GMP (Good manufacturing practice) systems. ${ }^{30}$

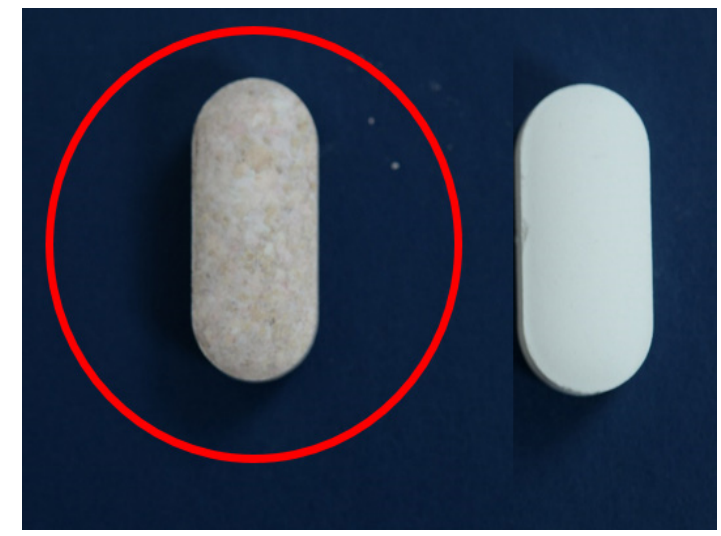

Figure 8 (b): Picture showing spoiled tablet (LHS) and good tablet from alternate batch number (RHS).

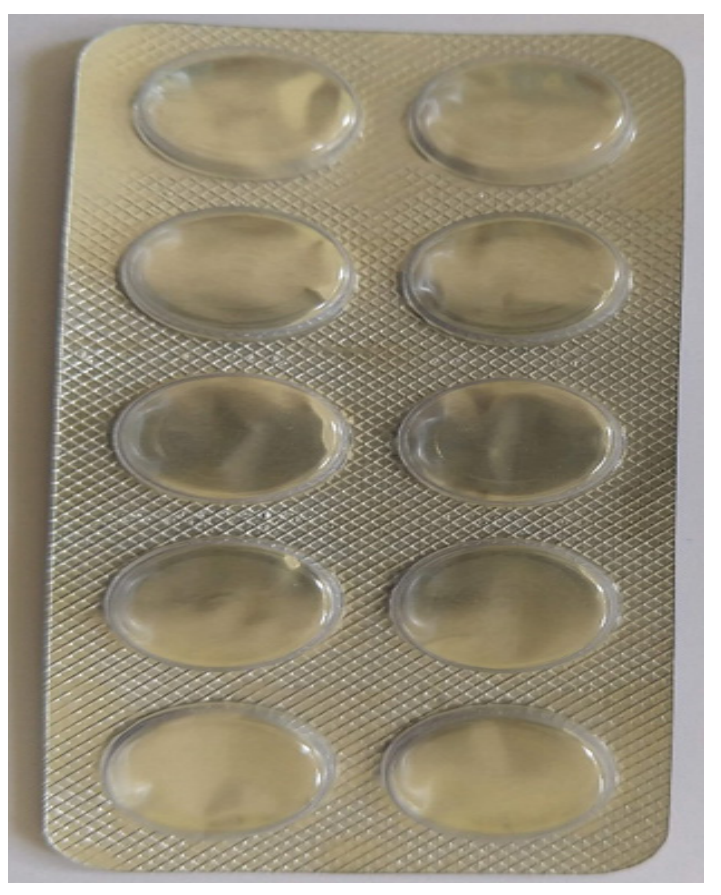

Figure 9: Empty blister. 
$>$ Ensure isolation of personnel during blister packaging operation from the equipment.

$>$ Refresh training on proper gowning procedures for personnel.

$>$ Ensure that the area where blister packaging operation is taking place is under positive pressure compared to the personnel area. ${ }^{31}$

$>$ Review/inspect the quality of the film-forming foil so that the same is free of any extraneous materials.

$>$ Ensure check on the quality of incoming materials before the release of the packaging material.

$>$ Ensure that the storage area of the film formers is having same degree of personnel control as the manufacturing area.

$>$ Reassess vendor qualification to ensure that the film supplying vendor is having the same degree of environmental control as a drug product manufacturer/formulator. ${ }^{32}$

\section{Clinical Significance}

Reduced patient compliance. ${ }^{33}$ The presence of hair follicle in the tablets may affect the therapeutic efficacy of the drug due to contamination (hair follicle, dandruff, etc.), psychological issues, or non-adherence.

CASE STUDY 4 - Investigation of soiled film coated tablet

Dosage form: Film coated tablets

Generic Name: Desloratadine tablets ${ }^{34}$

Therapeutic category: Antihistamine

Defects

a) The film coated tablets are soiled.

b) Powders adhered to film coated tablets. (Figure 7)

\section{Category of complaint: Major}

Probable root causes

- Damaged film coated tablet got packed in the blister. $^{12}$

- Improper inspection activity.

- Lower hardness of the tablet leading to highly friable tablets. ${ }^{3}$

- Very high coating solution flow rate leading to part of the tablet getting disintegrated.

- Improper / inadequate coating. ${ }^{1}$

\section{Remediation}

$>$ Review the manufacturing process to ensure that minimum tablet hardness is ensured before starting film coating operation.

$>$ Weight check of individual blister before cartoning.

$>$ Friability of the tablet to be ensured at less than $1 \%{ }^{14}$

$>$ Monitor coating solution flow rate and bed temperature during coating operation. ${ }^{35}$
$100 \%$ inspection of coated tablets for rejecting such defective tablets.

Clinical Significance: Patient acceptance may decrease. The soiled tablet may alter therapeutic efficacy due to the degradation of API. Reduced bioavailability due to altered dissolution. ${ }^{36}$ Patients may consume the contaminated tablet unknowingly leading to adverse events.

\section{CASE STUDY 5 - Investigation of blister containing spoiled tablets}

Dosage form: Uncoated caplet shaped tablets ${ }^{37}$

Generic Name: Uncoated tablets containing paracetamol and aceclofenac sodium ${ }^{38}$

Therapeutic category: Anti Pyretic and Antiinflammatory agent ${ }^{38}$

\section{Defects:}

a) A spoiled uncoated tablet found inside intact amber color blister pack. ${ }^{39}$

b) The patient complained of a tablet getting broken while taking it out from blister and bad appearance (Figure 8a \& 8b).

\section{Category of complaint: Critical}

Probable root causes

- Improperly dried granules leading to high/low moisture content.

- Manufacturing process error - inadequate granulation. ${ }^{40}$

- Change of grade of API and/or binder. ${ }^{41}$

- Inadequate compression setting.

\section{Discussion}

The probable root cause is inadequate granulation and/or mixing. The moisture content has to be very tightly controlled for paracetamol tablets to achieve required tablet hardness. Low/high moisture content of the tablet can lead to loss of hardness. There can also change of grade of API/binder as the tablets were discolored. Paracetamol supports microbial growth. A high-water content can lead to the promotion of microbial growth which in turn can cause discoloration. Paracetamol is a highly incompressible API. The use of a pre-compression stage before the compression stage can alleviate the problem to a certain extent.

\section{Remediation}

$>$ Review the manufacturing process for the batch and the grade of API/excipient used and loss on drying (LOD) of the tablets. Implement better manufacturing controls especially during granulation and drying. Review the grade of the API used.

> Adherence to GMP to ensure adequate cleaning before manufacturing to assure that basic cleanliness 
of the equipment is followed to prevent microbial growth. ${ }^{30}$

$>$ Evaluate the compression technique with a precompression facility to reduce challenges due to the incompressible nature of the API.

Clinical significance: Altered therapeutic efficacy due to the degradation of API. Reduced bioavailability due to improper granulation and spoiled medicine. ${ }^{42}$

\section{CASE STUDY 6 - Investigation of empty blister sheet}

Dosage form: Dispersible tablets ${ }^{37}$

Generic Name: Lactic acid bacillus, ${ }^{43}$ Folic acid ${ }^{44}$ and preconceptional intake of dietary folic acid (FA and Vitamin $\mathrm{B}_{12}{ }^{45}$

Therapeutic category: Anti-diarrhoeal, habitual constipation, flatulence and megaloblastic anemia ${ }^{46}$

Defects: Absence of tablets in blister pockets (Figure 9).

\section{Category of complaint: Minor}

\section{Probable root causes:}

- Blockage of discharge chute into the blister pockets ${ }^{47}$

- Empty hopper processed along with packaging

- Inadequate QC (Quality control) check before loading into secondary packaging material

\section{Remediation}

$>$ Proper steps need to be implemented after line clearance.

$>$ Camera to be installed to identify such blisters and $100 \%$ visual inspection of primary packing can also be performed.

$>$ Adequate checks need to be taken before packing into secondary packaging material

\section{Clinical Significance}

This will not have any significant impact on the patient. However, the patient may purchase and witness this defect after going to the house while taking the dose. This will be a problem for geriatric patients, as they have to visit the pharmacy shop again for replacing this blister.

To summarize, apart from listed defects or routine defects in tablet manufacturing as quoted in this article, we can positively assume that various types of quality issues can be encountered in marketed brands as well. Surprisingly, we encountered defects like broken and soiled film coated tablets, spoiled tablets, hair follicle with tablets and empty pocket, or empty blister. The observations were of a minor, major and critical types of defects. These may be stray incidents, but all the defects should be an eye-opener for manufacturing firms and are learning for improvising the manufacturing systems.

\section{Patient perception about quality complaints}

A drug is not only a chemical compound formed from the right blend of different elements but also trust, motivation builder for the consumer (patient). The drug is purchased with the faith that it would cure the patient of the ailment, or it would lead to better immunity. Like all manufacturing products, drugs also are subject to errors due to poor raw material quality, machine errors, or human errors. These errors can be summarized as medication errors and can have effects ranging from harmless and temporary to dangerous and permanent on the customer's mind. ${ }^{48,49}$ Little information is available on precise costs of medication errors. This study estimated the cost of medication errors reported by clinical pharmacists using a modified societal perspective. METHODS: Information on 779 medication errors was collected in the Medication Error Detection, Amelioration and Prevention (MEDAP).

The errors can be like an empty pocket in the blister and the consumer may point it out to the pharmacist and tell them to be careful, he may end up purchasing the drug again. But if the errors are of the type of broken tablets, or a hair follicle found in the tablet, then the impact may be high. The consumer may consume the tablet, which could have either been exposed to nature or may be contaminated. We need to understand the consumer attitude towards pharma products here. Research shows that influencers, reliability, awareness, corporate image and promotion are the five factors responsible for the purchase of OTC (Over the counter) pharmaceutical products. ${ }^{50}$ Awareness, reliability and corporate image form the attitude of the customer towards a brand. Post consumption, if there is a dissatisfaction/discomfort to the consumer, then a negative attitude is formed, leading to a change in consumer behavior towards that brand. This change will negatively affect the future consumption of the same drug. It is understood that attitudes do not change over time and they also bring consistency in the behavior. Moreover, this attitude is formed due to the cognitive component, i.e., the consumer's knowledge and experience, hence it may have a long-lasting impact on the consumer.

This attitude leads to a formation of perception called perceptual defense. Consumer perceptions are usually based either on prior personal experiences or reports of the previous experiences of others. The consumer may abandon the purchase of other drugs from the same brand/manufacturer. The consumer may start negative word of mouthing for the drug and/or manufacturer, which can lead to a dip in sales. ${ }^{51,52}$ The consumer may complain to the pharmacist and the doctor, leading to a 
lower prescription of the drug by the doctor and further less/no purchase by the pharmacist. This fall in sales can also lead to legal hurdles to the company, which will result in drug withdrawals, penalty, blacklisting of the company, loss of goodwill and financial losses also. ${ }^{53}$ Also, the impact of mistakes may be fatal with a geriatric patient as their immunity levels are less

A recent market report by KPMG points out that the consumer healthcare industry is growing fast and expected to touch 18 to 20 USD billion. If pharmaceutical companies wish to encash this segment, then they will have to bring in zero-defect drugs for the consumers. ${ }^{54}$

\section{CONCLUSION}

Regardless of the therapeutic use of medicine, none of the patients prefers a defective product to be purchased or expects any quality issue. The pharmaceutical industry deals with the life of human beings; the occurrence of defects in medicines is least anticipated by anyone working in the healthcare system. Tablets are the widely used dosage forms due to their affordability, stability and other user-friendly considerations. To prevent defects, the utmost care has to be taken during its genesis which starts from the procurement of API until it goes into primary packaging material. Just release of regulations by international agencies like US-FDA, WHO, ICH, EMA, etc. is not enough to ensure that quality and safety medicines are being manufactured and served to patients. It is important to implement Good Manufacturing Practices and abide by rules and regulations laid by them. Hence, to sum up, self-inspection, external audits, timely revision of Standard operating procedures, training to personnel, management of deviations and implementing Corrective and Preventive actions (CAPAs) have to be followed to prevent defects in medicines to ensure patients safety and achieve better therapeutic compliance. Authors also anticipate the investigation strategy followed in this article can be implemented in post marketing surveillance phase of clinical trials by randomly sampling the products from various parts of the country stored at extreme conditions (cold, hot, humid etc.) and comparing against reserve samples. This study also helps in developing and inculcating quality, ethics and GMP right from the academic setup, in addition the pharmaceutical companies may adopt this methodology for investigating the market complaints or defects obtained thereby adding value and quality to the medicinal product.

\section{ACKNOWLEDGEMENT}

Authors would like to thank the Audio-visual unit of Manipal Academy of Higher Education, Manipal, for capturing high definition photos and Radha Medicals and Manipal Drug House for their support.

\section{CONFLICT OF INTEREST}

The authors declare no conflict of interest.

\section{ABBREVIATIONS}

API: Active Pharmaceutical Ingredient; CAPAs: Corrective and Preventive actions; CDSCO: Central Drugs Standard Control Organization; EMA: European Medicines Agency; FDA: Food and Drug Administration; GRAS: Generally recognized as safe; ICH: The International Council for Harmonization of Technical Requirements for Pharmaceuticals for Human Use LHS: Left hand side; LOD: Loss on drying; MHRA: Medicines and Healthcare Regulatory Agency; OTC: Over the counter; PET: Poly ethylene tetra phthalate; PVC: Polyvinyl Chloride; RHS: Right hand side; TGA: Therapeutics Goods Administration; US-FDA: United States Food and Drug Administration; WHO: World health organization; WVTR: Water Vapor Transmission Rate.

\section{REFERENCES}

1. Aulton ME. Pharmaceutics: the science of dosage form design. $2^{\text {nd }}$ ed. Churchill Livingstone. 2002. [cited 2020 Apr 8]. 4, 9-11,445 p. Available from: http://localhost:8080/xmlui/handle/123456789/438

2. Center for Drug Evaluation and Research. Drug-FDA Glossary of Terms. FDA. 2020. [cited 2020 Apr 6]; Available from: https://www.fda.gov/drugs/ drug-approvals-and-databases/drugsfda-glossary-terms

3. Allen L, Ansel HC. Ansel's Pharmaceutical Dosage Forms and Drug Delivery Systems. 10 ${ }^{\text {th }}$ ed. Lippincott Williams and Wilkins. 2013;82:102-4.188-9, 271.

4. Tablets: General properties, Types, Advantages and Disadvantages. Pharmapproach.com. 2017. [cited 2020 Apr 9]. Available from: https://www. pharmapproach.com/solid-dosage-forms-tablets/

5. Dean DA, Evans ER, Hall IH. Pharmaceutical Packaging Technology. $2^{\text {nd }}$ ed. Taylor and Francis. 2000. [cited 2020 Apr 1]. 1-2 p. Available from: https:// public.ebookcentral.proquest.com/choice/publicfullrecord.aspx? $p=240114$

6. Pareek V, Khunteta DA. Pharmaceutical packaging: Current trends and future. Int J Pharm Pharm Sci. 2014;6(6):480-5.

7. Choudhary A. Packaging of Pharmaceutical Products: Pharmaceutical Guidelines. 2020. [cited 2020 Apr 11]. Available from: https://www. pharmaguideline.com/2018/03/packaging-of-pharmaceutical-products.html

8. Tippavajhala VK, Kumar L, Sathyanarayana MB, Thunga G, Chandran VP, Khan S, et al. A critical and comparative study on patient information leaflet, primary label and primary carton of a carbapenem dry powder injectable. Indian J Pharm Educ Res. 2019;53(1):178-85.

9. WHO. Guidelines on packaging for pharmaceutical products. 2002. Available from: https://apps.who.int/medicinedocs/documents/s19638en/s19638en.pdf 
10. Packaging modules for tablets and capsules. 2020. [cited 2020 Apr 11]. Available from: http://www.pharmabiz.com/NewsDetails. aspx?aid=90432\&sid=21

11. Pai K, Krishna T, Reddy M, Kishan YSS, Aditya V, Bhanuprakash G, et al. Physical evaluation of the uncoated tablets of glimepiride with different types of primary packaging. Research Journal of Pharmacy and Technology. 2012;5(3):404-7.

12. US Pharmacopeia. General Chapters: <1146> Packaging Practice-Repacking a single oral drug product into a unit-dose container. 2020. [cited $2020 \mathrm{Apr}$ 11]. Available from: http://ftp.uspbpep.com/v29240/usp29nf24s0_c1146.html

13. Types of Primary Packaging in Pharmaceuticals: Pharmaceutical Guidelines. 2020. [cited 2020 Apr 11]. Available from: https://www.pharmaguideline. com/2018/03/types-of-primary-packaging.html

14. Lachman L, Lieberman HA, Kanig JL. The theory and practice of industrial pharmacy. $3^{\text {rd }}$ ed. Lea and Febiger. 1986;299, 311-3,727-8.

15. Bhowmik D, Duraivel S. Tablet manufacturing processs and defects of tablets. Elixir Pharmacy. 2014;70:24368-74

16. Rana AS, Hari Kumar SL. Manufacturing defects of tablets: A review. J Drug Deliv Ther. 2013;3(6):200-6.

17. Felton LA. Remington: Essentials of Pharmaceutics. Philadelphia; London: Philadelphia College of Pharmacy: Pharmaceutical Press. 2013;614-6.

18. Lyseng-Williamson KA, Perry CM. Micronised purified flavonoid fraction: A review of its use in chronic venous insufficiency, venous ulcers and haemorrhoids. Drugs. 2003;63(1):71-100.

19. Venoactive Drugs. Clinical Gate. 2015. [cited 2020 Apr 12]. Available from: https://clinicalgate.com/venoactive-drugs/

20. Bhutani H, Mariappan TT, Singh S. Behavior of Uptake of Moisture by Drugs and Excipients under Accelerated Conditions of Temperature and Humidity in the Absence and the Presence of Light. :5. Packaged and unpackaged antituberculosis drug products. Pharmaceutical Technology. 2003;27(6):44.

21. Uddin S, Mamun AA, Tasnu T. In-process and finished products quality control tests for pharmaceutical tablets according to Pharmacopoeias. Journal of Pharmaceutical Research International. 2015;7.

22. Water Vapor Transmission Rate (WVTR) ASTM F1249. 2020. [cited 2020 Apr 12]. Available from: https://www.intertek.com/polymers/testlopedia/wvtrastm-f1249/

23. Stability testing of API. 2017. [cited 2020 Apr 12]. Available from: https://www. who.int/medicines/areas/quality_safety/quality_assurance/stblty-testingAPIsandFPPS-QAS17-694_12012017.pdf

24. Labib G. Novel levocetirizine $\mathrm{HCl}$ tablets with enhanced palatability: synergistic effect of combining taste modifiers and effervescence technique. Drug Des Devel Ther. 2015;9:5135.

25. Walsh GM. The anti-inflammatory effects of levocetirizine - are they clinically relevant or just an interesting additional effect?. Allergy Asthma Clin Immunol. 2009;5(1):14.

26. In-process checks during Packaging Operation of tablets and capsules [Online]. Pharmaceutical Guidance. 2020. [cited 2020 Apr 12]. Available from: https://www.pharmaguidances.com/in-process-checks-during-packagingoperation-of-tablets-and-capsules/

27. Duong NM, Chew MT, Demidenko S, Pham QH, Pham DK, Ooi MPL, et al. Vision inspection system for pharmaceuticals. In: 2014 IEEE Sensors Applications Symposium (SAS) [Online]. Queenstown, New Zealand: IEEE. 2014. [cited 2020 Apr 12]. p. 201-6. Available from: http://ieeexplore.ieee.org/ document/6798946/

28. Lamos EM, Stein SA, Davis SN. Combination of glibenclamide-metformin $\mathrm{HCl}$ for the treatment of type 2 diabetes mellitus. Expert Opin Pharmacother. 2012;13(17):2545-54.

29. SOP for Gowning Procedure for Quality Control: Pharmaceutical Guidelines. 2020. [cited 2020 Apr 12]. Available from: https://www.pharmaguideline. com/2011/07/sop-for-gowning-procedure.html

30. Ministry of Health and Welfare. Drugs and Cosmetics Act-1940, Schedule-M. $428 \mathrm{p}$.

31. Importance and Maintenance of Pressure Differential in Manufacturing Area: Pharmaceutical Guidelines [Online]. [cited 2020 Apr 12]. Available from: https://www.pharmaguideline.com/2013/09/importance-and-maintenance-ofpressure-differential.html

32. CFR - Code of Federal Regulations Title 21. Quality sytem regulations [Online]. [cited 2020 Apr 12]. Available from: https://www.accessdata.fda.gov/ scripts/cdrh/cfdocs/cfcfr/CFRSearch.cfm?fr=820.50

33. Martin LR, Williams SL, Haskard KB, Dimatteo MR. The challenge of patient adherence. Ther Clin Risk Manag. 2005;1(3):189-99.

34. Geha RS, Meltzer EO. Desloratadine: A new, nonsedating, oral antihistamine. J Allergy Clin Immunol. 2001;107(4):751-62.

35. Zellers ET, Han M. Effects of Temperature and Humidity on the Performance of Polymer-Coated Surface Acoustic Wave Vapor Sensor Arrays. Anal Chem. $1996 ; 68(14): 2409-18$.

36. Gupta S, Kesarla R, Omri A. Formulation strategies to improve the bioavailability of poorly absorbed drugs with special emphasis on selfemulsifying systems. ISRN Pharm. 2013;2013:848043.

37. Verma A, Gautam SP, Gautam T, Kaur S, Kanwar K. Recent Advancements in Tablet Technology: The need of hour. Journal name???3(12):7.

38. HB. Estimation of Paracetamol and aceclofenac in tablets by a novel ratio difference method. Res J Life Sci Bioinforma Pharm Chem Sci. 2019;5(1):18794.

39. Amber / Orange Blister Packaging PVC / PVDC Coated PVC Film Width 100-800mm. 2020. [cited 2020 Apr 12]. Available from: http://rigidpvcfilm.sell. everychina.com/p-103631908-amber-orange-blister-packaging-pvc-pvdccoated-pvc-film-width-100-800mm.html

40. Shanmugam S. Granulation techniques and technologies: Recent progresses. Biolmpacts BI. 2015;5(1):55-63.

41. Kraciuk R, Sznitowska M. Effect of different excipients on the physical characteristics of granules and tablets with carbamazepine prepared with polyethylene glycol 6000 by fluidized hot-melt granulation (FHMG). AAPS Pharm Sci Tech. 2011;12(4):1241-7.

42. Chowdary KPR, Enturi V, Kumar PS. Formulation development of nimesulide tablets by wet granulation and direct compression methods employing starch phosphate. Int J Chem Sci. 2011;9(4):1595-606

43. Kumari A, Catanzaro R, Marotta F. Clinical importance of lactic acid bacteria: a short review. Acta Bio-Medica Atenei Parm. 2011;82(3):177-80.

44. Barua S, Kuizon S, Junaid MA. Folic acid supplementation in pregnancy and implications in health and disease. J Biomed Sci. 2014;21(1):77.

45. Ermens AAM, Vlasveld LT, Lindemans J. Significance of elevated cobalamin (Vitamin B12) levels in blood. Clin Biochem. 2003;36(8):585-90.

46. Lactic Acid Bacillus / Folic - Uses, Side-effects, Reviews and Precautions tablet wise. 2020. [cited 2020 Apr 12]. Available from: https://www.tabletwise. com/medicine/lactic-acid-bacillus-folic-acid

47. Tablet Press: Types, functional parts, how it works, advantages. 2020. [cited 2020 Apr 12]. Available from: https://www.pharmapproach.com/tablet-press/

48. Samp JC, Touchette DR, Marinac JS, Kuo GM. Economic evaluation of the impact of medication errors reported by U.S. clinical pharmacists. Pharmacotherapy. 2014;34(4):350-7.

49. Walsh EK, Hansen CR, Sahm LJ, Kearney PM, Doherty E, Bradley CP. Economic impact of medication error: Asystematic review. Pharmacoepidemiol Drug Saf. 2017;26(5):481-97.

50. Srivastava RK, Wagh S. Factors impacting consumer purchase behaviour for pharmaceutical products. Int J Healthc Manag. 2017;1-9.

51. Richins ML. Negative Word-of-Mouth by Dissatisfied Consumers: A Pilot Study. J Mark. 1983;47(1):68-78.

52. Singh J, Pandya S. Exploring the Effects of Consumers' Dissatisfaction Level on Complaint Behaviours. Eur J Mark. 1991;25(9):7-21.

53. Diamond AL, Laurence DR. Product liability in respect of drugs. Br Med J Clin Res Ed. 1985;290(6465):365-8.

54. McKinsey and Company. India Pharma 2020 Propelling Access and Acceptance Realizing True Potential. 2020. [cited 2020 Apr 16]. Available from: https://www.mckinsey.com/ /media/mckinsey/dotcom/client_service/ Pharma\%20and\%20Medical\%20Products/PMP\%20NEW/PDFs/778886_ India_Pharma_2020_Propelling_Access_and_Acceptance_Realising_True_ Potential.ashx e 


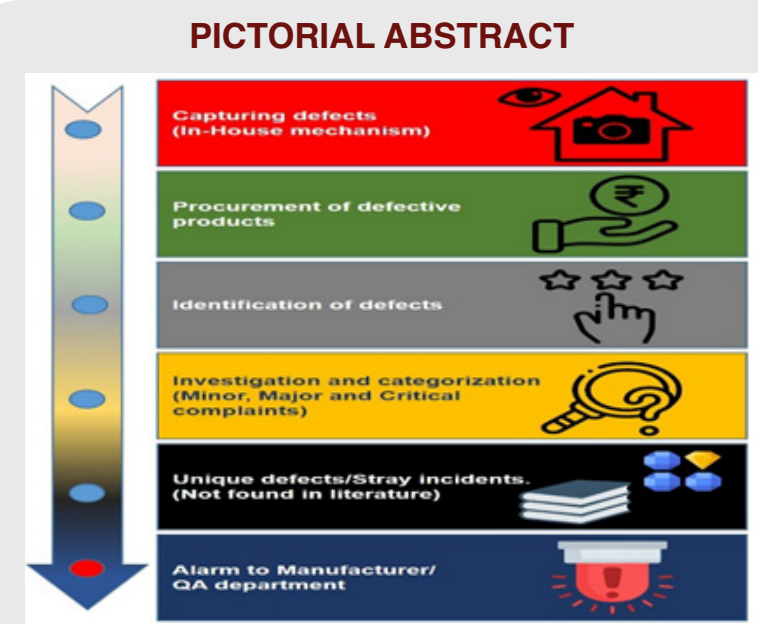

\section{SUMMARY}

The defects reported in this research work were captured by using the In-House mechanism. Products were procured, defects were identified and went through a process of investigation which categorized defects into minor, major and critical complaints. The defects identified are unique enough that they are not found in any standard textbooks and literature. The key message given through this article to the Pharmaceutical industry is that it is necessary for the implementation and practice of rules and regulation laid by regulatory agencies which ensure the quality of drugs and safety of patients.

\section{About Authors}

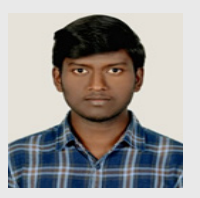

Hemanth KG is currently pursuing M.Pharm in Department of Pharmaceutics, Manipal College of Pharmaceutical Sciences, Manipal Academy of Higher Education, Manipal. He completed his BPharm from Al-Ameen College of Pharmacy, Bangalore. He was an Intern in Medical Communications, Novartis HealthCare Pvt Ltd., Hyderabad. He has received Merit scholarship from TATA Trusts for his outstanding score in $1^{\text {st }}$ year M.Pharm. His key interest areas include, 3D Printing, Novel Drug Delivery Systems, Regulatory affairs and Artificial Intelligence.

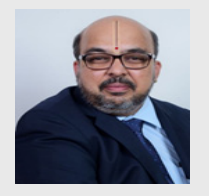

Mr. Ravindra Shenoy $U$ is a faculty at Department of Commerce, MAHE, Manipal, His research interests include Ethical leadership, Spirituality in leadership, Indology, Vedic Management, Business Ethics and Consumer Behaviour. He has worked with corporates including Tata Group, Gillette India and ICFAI. Mr, Shenoy has published 4 research papers and 1 book chapter. Being a corporate soft skills trainer certified by TCS, he has conducted more than 45 workshops on soft skills for both students and corporate audience. Mr. Shenoy is also a member of few prestigious international bodies including Association of Leadership Educators, Council for Research in Values and Philosophy, Harvard Business Review Advisory Council, The Society of Corporate Compliance and Ethics and Advisory Committee at ISOL (Integrating Spirituality and Organizational Leadership) Asia. He is also a recipient of Shiksha Rattan.

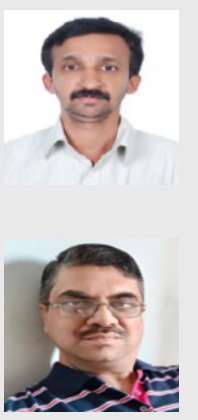

Dr. Girish Thunga is a faculty at Department of Pharmacy Practice, Manipal College of Pharmaceutical Sciences, MAHE, Manipal. He teaches undergraduate students and post graduate students of Pharmacy. His Area of academic specialization is Drug Safety and Clinical Toxicology. $\mathrm{He}$ is presently guiding few Ph.D. students in various challenging topics; He has 10 years of total experience in academics. He has published several papers in journals of high repute, several book chapters and have presented papers in national and international conferences.

Mr. Sudeep Kumar Agrawal is the Vice president - Product Development at Sun Pharmaceutical Industries Ltd., Vadodara. He has 25 years of total vast experience in product development in various Pharmaceutical majors of high repute. Mr. Agrawal has successfully submitted over 60 products to various regulated markets, many of which are para four submissions. Additionally, he also has several approvals for complex injectable products both in regulated and non-regulated markets. He has several patents to his credit.

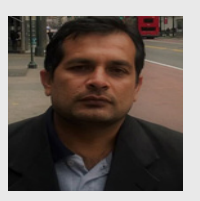

Mr. Mahendra Joshi is Co-founder and Director of IDRS Labs Pvt. Ltd., Bengaluru. He has about 17 years of total experience in Pharma Industries of High repute. Mr Joshi has published several papers in journals of high repute and have presented papers in national and international conference. He has several patents to his credit, He is recipient of BMS Crystal Award for outstanding technical leadership $\mathrm{He}$ is the winner of Indian Leadership Award for Industrial Development for the year 2014 awarded by AIAF, New Delhi, India.

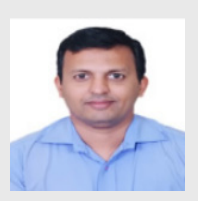

Dr. Muddukrishna B.S is a faculty in the Department of Pharmaceutical Quality Assurance, Manipal College of Pharmaceutical Sciences, MAHE, Manipal. He teaches pharmaceutical analysis to undergraduate students and pharmaceutical quality assurance and management to post graduate students of Pharmacy. He has $19+$ years of total experience in academics, Research and Development, Laboratory operations and Quality Assurance in organizations of high repute. He has published several papers in journals of high repute, he has published several book chapters and have presented papers in national and international conference. He Received several awards for his research activities. 


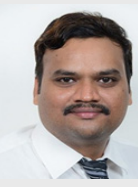

Dr. Vamshi Krishna $\mathbf{T}$ is faculty at Department of Pharmaceutics, Manipal College of Pharmaceutical Sciences, MAHE, Manipal. His academic interests include the areas of Pharmaceutics, Physical Pharmaceutics and Pharmacokinetics, Advanced Bio pharmaceutics and Pharmacokinetics, Modern Pharmaceutics, Pharmaceutical Product Development. He has briefly worked for Advinus Therapeutics Pvt. Ltd. and has spent about 12 years in academics. Dr. Vamshi Krishna has published over 44 research papers and articles. Dr. Vamshi Krishna completed his Post-doctoral research fellowship on the project entitled "Confocal Raman spectroscopic analysis of cosmetic permeation through human skin" from the Laboratory of Biomedical Vibrational Spectroscopy, Universidade do Vale do Paraiba, Sao Jose Dos Campos, SP, Brazil, in July 2016. He is also a life member of Association.

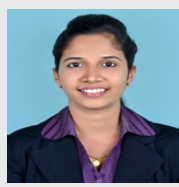

Ms. Abhinaya $\mathbf{N}$ is presently pursuing Ph.D. in the Department of Pharmaceutics, Manipal College of Pharmaceutical Sciences, Manipal Academy of Higher Education, Manipal, India. She completed her Bachelor's and Master's degree from Manipal College of Pharmaceutical Sciences, Manipal University. Her area of research expertise includes Industrial pharmacy, Formulation research and development, Quality Assurance and Good Manufacturing Practices (GMP). She has published research articles and case reports in peer-reviewed journals.

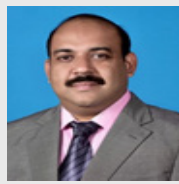

Dr. Girish Pai Kulyadi is faculty at Department of Pharmaceutics, Manipal College of Pharmaceutical Sciences, Manipal Academy of Higher Education, Manipal, India. He has more than 20 years of professional experience both in pharma industry and academia. His area of research expertise include formulation development of novel drug delivery systems, Plant Operations, Advanced Industrial Pharmacy, Validation Concepts, Stability Studies of Drug Products etc. He has published more than 60 research and review articles in peer reviewed journals.

Cite this article: Hemanth KG, Shenoy RU, Thunga G, Agrawal SK, Joshi M, Sathyanarayana MB, et al. Solid Dosage Forms: A Detailed Research on Non-conforming Product Quality. Indian J of Pharmaceutical Education and Research. 2020;54(3s):s473-s484. 